\title{
Men and masculinities \\ in academia
}

\section{Towards gender-sensitive perspectives, processes, policies and practices}

Jeff Hearn

\section{Introduction}

Academia is a complex site involving many agents within multi-organisations in which the inter-organisational relations operate locally, nationally and transnationally. In seeking to understand the gender dimension of academia, it is necessary to understand gender power relations in societies and institutions. This in turn means developing an understanding of men and masculinities, as well as women and femininities. Thus, gender and gender relations are not synonyms for women; they not only concern women and girls but also men and boys, and further gender/sexual categories, notably LGBT*IQ+, including non-binary, agender and asexual people. This kind of relational gender power perspective applies in many arenas but takes particular forms in academia. Approaching gender dimensions in such ways is relevant to the conduct of academic institutions, organisations and management, research development and research processes and the specific doing of academic work.

Gender inequality in academia is often framed with a sole focus on women, either women's experiences or seeing women as the problem who need to be changed. The debate can also be framed in terms of complementary gender relations as problematic, hence change requiring gender mainstreaming, without any explicit commitment to feminist theory and practice. Less frequently, the focus can be shifted onto men as the problem and the need to change men within gender power relations. This chapter focuses on neither 'women as the problem' nor 'gender mainstreaming' as the solution. Rather it concentrates on gendering men, or 'the problem of men' in academia. In engaging with the problematic that men in academia are gendered too, discussion focuses on three key interconnected aspects: perspectives on studies of men and masculinities; processes in universities, higher education and science that can be analysed through a critical analysis of men and masculinities; and policies and practices: what is to be done individually, organisationally and nationally, in academia?

\section{Changing perspectives on studying men and masculinities}

Before proceeding to discuss some key features of recent studies on men and masculinities, three basic points should be noted. First, studies on men and masculinity 
are not new and have often studied men implicitly and/or without a clear critical stance; second, studying men and masculinity is, in itself, no guarantee of criticality; and third, the man or men question is well-documented in feminist and critical gender theory and practice.

The last 50 years have seen an expansion of critical research on men and masculinities, sometimes referred to as the sub-field of Critical Studies on Men and Masculinities (CSMM), as part of women's and gender studies (Hearn and Howson 2019). CSMM is a broad umbrella term for different kinds of studies of men and masculinities that are distinct from malestream studies (O'Brien 1981), which are opposed to non-gendered, non-feminist or anti-feminist scholarship. CSMM refers to critical, explicitly gendered studies of men and masculinities that engage with feminist critiques, but also some men's positive responses to feminism, and further critical perspectives such as poststructuralism, postcolonialism and drawing from gay, queer, trans, intersex and non-binary positions. Hence, studies within CSMM range across many perspectives, paradigms and disciplines, from masculine psychology to broad societal and collective analyses of men, including ethnographies of particular groups and activities of men and investigations of masculinities in specific discourses. Certain themes have been stressed, for example work and family, sometimes posed in contradiction with what are often assumed to be dominant definitions and priorities of men. Much research has been local, personal, bodily, immediate, interpersonal or ethnographic, on specific groups of men and boys in different parts of the world. Increasingly, there is a further turn to the 'big picture' of globalisation (Connell 1993, 1998), worldcentred approaches (Connell 2014), transnational patriarchies and transnational change (Hearn 2015). These diverse kinds of research studies are all relevant for the analysis and change of men and masculinities in academia.

More generally, the explicit 'naming men as men' (Hanmer 1990; Collinson and Hearn 1994) has been made, not to essentialise or reify men but to see men and masculinities as an object of critique and critical interrogation. The idea that the gender of men derives from a fixed, inner trait or core is antagonistic to CSMM. Accordingly, it is necessary to distinguish men as 'objects' of study, and men as 'subjects' or doers of studies. Importantly, the sub-field of CSMM is certainly not the preserve or property of men, as promoted in some ambiguous or anti-feminist versions of men's studies. Rather, CSMM comprise studies by all genders.

The broad critical approach to men and masculinities that has developed in CSMM can be characterised as: a critical explicit focus on men and masculinities, informed by feminist, gay, queer and other critical gender scholarship; understanding men and masculinities as gendered, socially constructed, not just 'naturally this way', variable and changing across, space, within societies and across the life course and biographies; emphasising men's differential relations to gendered power; spanning the material and the discursive in analysis; and taking account of the intersections of gender and other social divisions (Connell et al 2005).

Overall, CSMM encompass historical, cultural, relational, materialist, deconstructive, anti-essentialist studies on men and masculinities (Hearn and Pringle 2006). In debates in and around CSMM, the most cited approach is what can be 
called masculinities theory (Carrigan et al 1985; Connell 1995) in which various masculinities are framed in relation to the theorising of patriarchy and patriarchal relations. Within this approach, the concept of hegemonic masculinity has been central, while other concepts, such as complicit masculinity, are less well developed. Hegemonic masculinity has been defined as:

the configuration of gender practice which embodies the currently accepted answer to the problem of legitimacy of patriarchy, which guarantees (or is taken to guarantee) the dominant position of men and the subordination of women.

(Connell 1995, 77)

Key features of this approach centre on critiques of sex role theory together with an analysis of concepts of masculinities and power. The approach also emphasises men's unequal relations to men as well as men's relations to women and the implications of gay scholarship and sexual hierarchies more generally, distinguishing between hegemonic, complicit, subordinated and marginalised masculinities. This approach also calls for analysis of institutional and social, interpersonal and psychodynamic aspects of masculinities.

Masculinities theory has been extremely influential within CSMM and beyond, with applications and different interpretations of hegemonic masculinity in theoretical, empirical and policy studies (Connell and Messerschmidt 2005; Hearn et al 2012; Bridges and Pascoe 2014; Matthews 2016). There are also various critiques of masculinities theory and the concepts of masculinity and hegemonic masculinity, such as lack of clarity in what masculinity/ masculinities mean. Additionally, comparative, postcolonial, transnational, queer and other critical approaches complicate a unified theory of men and masculinities; and 'hegemonic masculinity' is often a heuristic device rather than a precise concept. Thus:

the concept of hegemony has generally been employed in too restricted a way; the focus on masculinity is too narrow. Instead, it is time to go back from masculinity to men, to examine the hegemony of men and about men. The hegemony of men seeks to address the double complexity that men are both a social category formed by the gender system and dominant collective and individual agents of social practices.

(Hearn 2004, 59, emphasis in original)

To summarise, CSMM involves, first, the critical gendering of men, the 'naming men as men' and, simultaneously, problematising and deconstructing masculinities and the social category of men.

\section{Changing processes on men and masculinities in academia}

Debates about gender in academia have typically focused on women and girls, as when discussing why more girls do not take up science, engineering and 
technology subjects. One might imagine that it is difficult to talk about academia without discussing the power, positions and constructions of men and masculinities, but that is not so. Instead, extensive scientific and popular debate on 'failing boys' in schools continues to be the focus. Men in academia remains unproblematised. Indeed, many debates and documents on gender equality in academia are strangely silent on questions of men, masculinities and male majorities, especially those that operate at senior and leadership levels. For example, there are many excellent studies and reports on gender and science (European Commission 2009; Caprile et al 2012), some funded by the European Commission. Yet few have much to say about men and masculinities and their part in maintaining inequalities within science and higher education systems. While many reports include a mass of highly relevant information, few if any demands are made on changing men, or masculinities. Consequently, men continue to be let off the hook. Men are typically an 'absent presence', even in critical studies of academia. Implicit references are often wrapped up in gender-neutral characterisations of institutions, as if there are 'non-gendered universities + women'. Without attending to such themes, how likely is it to lead to reduced gender inequalities in higher education? Naming men as men (Hanmer 1990; Collinson and Hearn 1994) and naming male privilege (Bulumulle 2015) is still an obvious, yet awkward and uncomfortable, task for many in academia.

Debates on gender equality in academia have focused on three main forms of gendered processes and politics:

- gendered individuals: Who does what? Who does academic work? Who are the leaders, inventors, followers, researchers, teachers, support workers? How are individual identities and careers gendered?;

- gendered organising and organisations: how academia is organised and managed within organisations and organisational cultures; and

- gendered knowledge: the relevance of gender for the construction of academic knowledge itself, in the research process and knowledge production.

Taking each of these processes in order: first, the gendering of men and masculinities in academia can be understood by way of the construction of individuals and their identities. Within academia there are many sites where different masculinities are reproduced: for administrators, academics, managers and students. In studying the conduct of jurisprudence in universities, for example, Collier (1998) catalogued different kinds of male academics and academic masculinities: the nutty professor; the administrator; the new entrepreneur; the sexual predator; the young man in a hurry; the infantilised intellectual; the empire builder; the aloof cynic; the gentleman intellectual; the academic couple; even the profeminist (Collier 2002). Arguably, the new entrepreneur and the young man in a hurry have become more prominent in the neoliberal university, where age and status are no longer so strictly self-reinforcing. To this list, one might note further academic masculinities in all subject areas such as: the misogynist, the stealer of ideas; the 
unsuccessful academic; the non-researching research manager; the gatekeeper; and the equality supporter, whether active, passive or simply hypocritical.

The focus on the individual is not only a matter of male academic identity, it also concerns individual careers and evaluations. For example, there is now significant evidence from Swedish surveys of the relative advantages that accrue to male doctoral students compared to their female counterparts. This is in a range of areas: health, stress, parenthood, discrimination, sexual harassment, integration in the academic environment, doctoral work and career coaching. The overall results indicate a more positive, supportive doctoral educational environment for men than women (HSV 2003, 2008; UKÄ 2016; Hearn and Husu 2019). Individual academic evaluation may be gender-biased in various ways, for example, with scoring of men higher than women in assessing CVs and differential letters of recommendation (Madera et al 2009). A more complex process is raised by a study of 168 life scientists in ecology and evolutionary biology, showing clear differences in publication rates between men and women in early careers, with consequences for subsequent citation (see Chapters 1 and 2). The use of the apparently neutral $\mathrm{h}$-index as a measure of research performance (the number of published papers, $h$, by a given scientist that have received ' $h$ ' or more citations) favours men. The h-index is highly correlated with the quantity of research output. Women assessed thus are likely to suffer in comparison with men (Symonds et al 2006). Men still tend to publish more papers than women, even after accounting for mitigating factors (Ding et al 2006). These processes interconnect with organisational contexts.

Second, gendering men and masculinities in academia is important in terms of how academic institutions and workplaces operate. Historically, academic organisations have been characterised by the relative age, class and ethnic homogeneity and homosociality of certain men. Homosociality encapsulates men's greater valuation of men, and preference for men and men's company (Lipman-Blumen 1976), the transfers of power and information, emotional charge, and emulation and imitation between men; and the dispensability of individual men. It is a useful concept to consider the ways of organising of men in academic management. Similarly, the notion of 'cultural cloning' (Essed and Goldberg 2002) has been applied more intersectionally to analyse working in and between academic institutions. The historical legacy and current reality of men-men relations, men's networks and male bonding are obvious in most academic institutions. The legacy of homogeneity and homosociality of certain men has only been displaced partially in relatively recent times. Even with moves to more technocratic forms of management (Hearn 2001), academia remains predominantly a site of men's power, privilege and mutual support (Bulumulle 2015).

Contemporary academia continues much of this legacy, but with some further features. For a start, academia is characterised by strong age, ethnic and gender-differentiation, both vertically and horizontally. In many cases, there are relatively fixed layers of older professorial and senior staff, predominantly men, together with shifting, temporary and often more diverse populations of women and men members among students and less well-established staff. Furthermore, 
some academic institutions and social sites, such as some university departments and conferences, involve both formality and informality, that also bring social and interpersonal ambiguities. In some extreme instances this provides room for men's harassment and misuse of power towards typically younger students and researchers. These, in turn, may mean the presence of hierarchical, age, gender, social, sexual and intense emotional dynamics. In sum, academia houses both strong pressures and opportunities to conform and, at least in some academic traditions, occasions for subversion of that conformity.

A key aspect of the gendered operations of academia is how men act as managers, gatekeepers and leaders more generally. Considered in a broad international perspective, there are very large national and societal variations in the extent to which men dominate professoriates, headships of departments, rectorates and decision-making bodies responsible for awarding research funding (European Commission 2019). In some EU countries, for example Belgium, Croatia, Cyprus, Czech Republic, Estonia and Greece, such key positions are still overwhelmingly 'men's business' (European Commission 2019) (see Chapter 1).

Gendered processes in research and funding are not just about individual careers. They are more embedded organisational processes. These include, not only the relative rate of research funding success of women and men applicants, but also relative gender rates of application (affected by position, status and organisational support and facilitation), relative rates and patterns of publication, citation and funds awarded, according to gender. Some studies of funding processes, for example, Wennerås and Wold's (1997) study showed how men were favoured in the allocation of state funding of medical research in Sweden. However, a similar UK study by the Wellcome Trust (Wellcome Trust 1997), while not finding gender bias, noted women's lower rate of application for research funding. Such studies have been influential in questioning and sometimes reforming assessment and selection procedures. A meta-analysis of 21 studies found evidence of robust gender differences in grant award procedures:

Even though the estimates of the gender effect vary substantially from study to study, the model estimation shows that all in all, among grant applicants men have statistically significant greater odds of receiving grants than women by about 7 per cent.

(Bornmann et al 2007, 2)

In many countries, basic information is still lacking on the gendering of these processes and the part that different men play as gatekeepers in research funding decisions (European Commission 2009).

Men's managerial power and influence, along with managerial masculinities in academia, encompass the impact of men's actions on appointments, promotions, distribution of academic resources and priorities. Two particular issues of interest are: the transition from being primarily a senior researcher to an academic manager; and the question of which particular women, with which particular gender 
positioning, are supported and sponsored by men in academic management. Masculine or masculinist cultures may also be reproduced at the level of departmental or research teams, in terms of local work cultures: as 'family' (for example, patriarchal, paternalist) or 'gang' (for example, sporty, nerd), which may undervalue or exclude women's contribution and leadership.

Third, the gendering of men and masculinities extends to knowledge production, research content, theory development, concepts, research directions and priorities. The institutional structures and contexts of academia have always had differential impacts on men's and women's opportunities to engage in academic activities (Bowling and Martin 1985; Schiebinger 1987). The relevance of explicitly gendered thinking on men and masculinities is relatively well-researched and recognised in relation to technology (Cockburn 1985; Willinsky 2000; Lohan and Faulkner 2004) and, to some extent, in relation to medicine (Rosenfeld and Faircloth 2006). For example, cardiovascular disease has often been presented as a male disease but is in fact a major disease of women; osteoporosis is sometimes seen as a female disease but is a major disease of later male life. Until the late 1990s, women were routinely excluded from scientific studies since it was assumed that the results would apply equally to males and females. This assumption was shown in many instances to be wrong (Greenspan et al 2007).

Moreover, each facet and stage of the research process and knowledge production, in terms of both substantive academic and theoretical practices, is susceptible to gendered structuring, positionings and interactions of men and masculinities. Shifting this process means paying greater attention to the gendered aspects of research content and sex/gender analysis in scientific knowledge production; and challenging assumptions of gender neutrality within supposedly 'objective' mainstream scientific excellence. It also calls for the further development of critical studies on men and masculinities themselves (see Chapter 14).

\section{Changing policies and practices on men and masculinities in academia}

Naming men as men in academia is both a matter of analysis and of policy and practice. So, what is to be done by and with men? How can men contribute to gender equality and how are men affected by gender (in)equality in academia? Men are not a homogenous group and the long-used binary assumptions no longer prevail.

\section{Individual and interpersonal change}

One arena for action is to focus on changing individuals and interpersonal relations. Men in academia are probably not so very different to other men. Some may be a little more intellectual, work-oriented, more defended, more defensive and they may be able to engage in complex forms of resistance. Men's practices can be seen as paralleling closely how men may respond to gender equality more generally on a spectrum from outright rejection and hostility to welcoming; 
anti-feminist, unhelpful to facilitative, profeminist (Messner 1997; Egeberg et al 2009). Men move along such dimensions in gendered practices according to political and organisational pressures and conditions. Men, as a social group, are relatively privileged but some men seek to act against gender inequality, supporting women and appointing feminists. Unreconstructed men persist, as when, for example, supposedly 'critical' male academics say proudly they know nothing about gender.

There are many ways in which men can avoid being concerned with or resist gender issues and gender equality. Typical expressions used to avoid and resist 'naming men as men' in academia include:

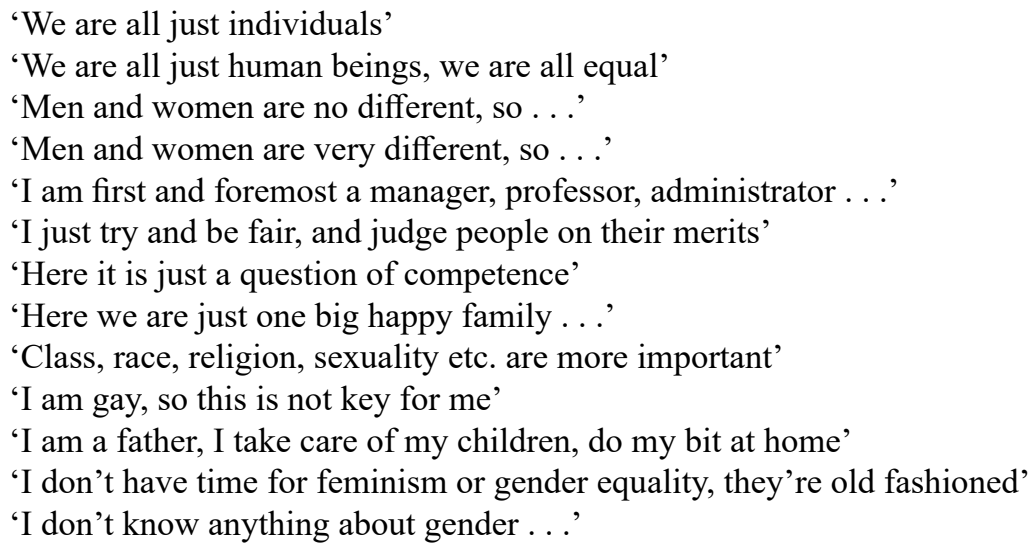

There are men in academia who may be familiar with and even embrace feminism and gender equality but cannot be relied upon to act against men's interests or to demonstrate solidarity with women. Men acting against gender inequality are less usual: appointing feminist women, supporting women, critically examining men in their own scholarly work. They have a key role to play in breaking silence, in being persistent.

Common pitfalls in mixed-gender groups in academia, as elsewhere, are many and varied. They include 'hogging the show' and being the continual problemsolver; focusing only on task and content, to the exclusion of giving support and acknowledging one's own and others' feelings; negativity and falling back on formal power positions; listening only to other men; intransigence and dogmatism; condescension and paternalism; using sexuality to manipulate women; and seeking attention and support from women while running the show; storing key information for their own use; and speaking on behalf of others (Moyer and Tuttle 1983). These have a good deal in common with the five 'master suppression techniques' described by Ås (1978) namely: making invisible, using ridicule, withholding information, double binding, and heaping blame and putting to shame-later supplemented by objectifying, and using force and the threat of force. Against such actions, Moyer and Tuttle (1983) were early advocates of responsible actions for 
men to oppose 'mansplaining'. Recommended actions include: limiting talking time to a fair share; not interrupting; being a good listener; not speaking on every subject; not putting others down; and intervening to interrupt others' oppressive behaviour. Such actions can all contribute to nurturing more democratic group and organisational processes.

\section{Organisational change}

At the organisational level, systemic and structural change is still needed. According to the ETAN report (European Commission 2000), the principles of gender mainstreaming in scientific institutions are: building equality into the culture and organisations, treating employees as whole persons, respect and human dignity (anti-discrimination), participation and consultation, and visioning. The main tools recommended for realising these goals include: gender equality indicators, gender proofing and gender impact assessment, ownership of gender equality within all organisational levels, gender monitoring for employers, enacting EU member-state laws on gender balance in decision-making and access to public records, removing the laws impeding women's scientific careers, providing awareness-raising and training.

Structural gender change in universities also requires changing men and masculinities. Local and national targets for maximum numbers of men in academic management, evaluation committees and similar bodies need to be set. If there are more women in academic management and gatekeeping, there will be less men there. Such changes might increase the likelihood of more research funding flowing to women and into fields where women are under-represented with less to men and for fields where men are over-represented. Changing men in academia, academic leadership and academic evaluation means ensuring that men have academic and professional knowledge and training on gender and power issues and do not reproduce sexism and gender domination in their own actions and behaviour. It also means changing dominant models of masculinity in academia, for example, by way of gender equality training and similar interventions to address questions of male identity and men's prejudices, behaviours and gender awareness. It also calls for an awareness of how academic organisations can reproduce dominant male values, and ways of promoting positive change. These interventions would likely have further impacts on men's own research and teaching.

Many further organisational policies and actions follow from naming and deconstructing men, such as reviewing a culture of long hours' work and normalising caring masculinities at home and work (Scambor et al 2013 and Chapter 5). Instituting policy and practice on issues of sexuality, gender identity, harassment, bullying and violence; and attending to men's intersectional relations, for example in relation to age, class, mental health and sexuality are equally important (Hearn and Collinson 2009). Importantly, resource allocation policy can be linked to gender equality, for example, shifting budgets in inverse proportion to the ratio of men to women. In summary, it is necessary to investigate how men can assist in not 
blocking, not resisting, gender equality policies, to ask men where they stand and to change men!

\section{National and transnational change}

Finally, there is the question of national and transnational contexts. Personal experience attests that the situation on men, masculinities and gender equality can appear to be different in different countries, with distinct national policy frameworks. Academia is increasingly sustained by transnational reserve armies of postdoctoral academic labourers pursuing gendered and generational precarious, mobile 'early' careers through short-term research projects and part-time teaching, sometimes over an extended period and multiple sites or continents (Hearn and Husu 2019; Murgia and Poggio 2019 and Chapter 2). In this academic world, control may easily shift from direct patriarchal management in universities towards greater self-monitoring by more docile or supposedly 'autonomous' academics, existing within transnational academic patriarchies.

Furthermore, academia is increasingly subject to internationalisation, transnational trends and influences. These include moves to neoliberal management, work intensity, monitoring and surveillance, with less unit resources and more standardised measures. Academic institutions are positioning themselves in terms of competitive status through league tables and the prioritising of publications (Chapter 14). There is also the domination of north/west/anglo 'knowledge' and an obsession with 'excellence' in research. In the contemporary academic world, the individual academic institution is not necessarily the primary or most important unit. It exists within tighter inter-organisational relations between universities, through networks, partnerships and associations. Scientific knowledge production and global academic value chains are developed through a mix of scientific hubs and dispersed transnational networks. All these developments are to be understood more fully by highlighting critical analysis and practice in relation to men and masculinities. Men and masculinities now operate within the complex relations between transnational neoliberal academic patriarchies, neoliberal (supposedly 'autonomous') universities and constructions of neoliberal, individual and individualist 'autonomous' masculinities (Hearn 2017). These conditions demand new, creative responses for changing men nationally and transnationally. The problem of men in academia is national and transnational, not just a matter of individual male academics or individual male-dominated universities and academic institutions.

\section{Conclusion}

This chapter shifts the debates on gender-sensitive academia to encompass critical approaches to men and masculinities. This means addressing critical research studies and theoretical developments, both general and more focused on academia, along with changes in policy development and everyday practice. The 
interventions outlined here are on and around men and masculinities at many levels. They collectively assist movements towards more gender-sensitive academic institutions. By shifting the perspective from a sole focus on women as the 'problem' to be reformed, or versions of gender-neutral, gender mainstreaming and structural change where men and masculinities are distinctly and strangely absent, knowledge production itself is likely to become less patriarchal, less sexist, less ungendered and ultimately more scientific.

\section{References}

Ås, B. (1978) Hersketeknikker, Kjerringråd, 3, 17-21.

Bornmann, L., Mutz, R. and Daniel, H. (2007) Gender differences in grant peer review: A meta-analysis. Journal of Informetrics, 1 (3), 226-238.

Bowling, J. and Martin, B. (1985) Science: A masculine disorder? Science and Public Policy, 12 (6), 308-316.

Bridges, T. and Pascoe, C. (2014) Hybrid masculinities: New directions in the sociology of men and masculinities, Sociology Compass, 8 (3), 246-258.

Bulumulle, K. (2015) Interrogating what is male privilege in the academy, Doctoral dissertation, University of Adelaide, Adelaide.

Caprile, M., Addis, E., Castaño, C., Klinge, I., Larios, M., Meulders, D., Müller, J., O’Dorchai, S., Palasik, M., Plasman, R., Roivas, S., Sagebiel, F., Schiebinger., L., Vallès, N. and Vázquez-Cupeiro, S. (eds) (2012) Meta-analysis of gender and science research: Synthesis report, European Commission, Brussels.

Carrigan, T., Connell, R. and Lee, J. (1985) Towards a new sociology of masculinity, Theory and Society, 14 (5), 551-604.

Cockburn, C. (1985) Machinery of dominance: Women, men, and technical know-how, Pluto, London.

Collier, R. (1998) 'Nutty professors', 'men in suits' and 'new entrepreneurs': Corporeality, subjectivity and change in the law school and legal practice, Social \& Legal Studies, 7 (1), 27-53.

Collier, R. (2002) The changing university and the (legal) academic career-rethinking the 'private life' of the law school, Legal Studies, 22 (1), 1-32.

Collinson, D. and Hearn, J. (1994) Naming men as men: Implications for work, organizations and management, Gender, Work and Organization, 1 (1), 2-22.

Connell, R. (1993) The big picture: Masculinities in recent world history, Theory and Society, 22 (5), 597-623.

Connell, R. (1995) Masculinities, Polity, Cambridge.

Connell, R. (1998) Masculinities and globalization, Men and Masculinities, 1 (1), 3-23.

Connell, R. (2014) Margin becoming centre: For a world-centred rethinking of masculinities, NORMA: The International Journal for Masculinity Studies, 9 (4), 217-231.

Connell, R., Hearn, J. and Kimmel, M. (2005) Introduction, in M. Kimmel, J. Hearn and R. Connell (eds), Handbook of studies on men and masculinities, Sage, Thousand Oaks, CA, 1-12.

Connell, R. and Messerschmidt, J. (2005) Hegemonic masculinity: Rethinking the concept, Gender \& Society, 19 (6), 829-859.

Ding, W., Murray, F. and Stuart, T. (2006) Gender differences in patenting in the academic life sciences, Science, 313 (5787), 665-667. 
Egeberg Holmgren, L. and Hearn, J. (2009) Framing 'men in feminism': Theoretical locations, local contexts and practical passings in men's gender-conscious positionings on gender equality and feminism, Journal of Gender Studies, 18 (4), 403-418.

Essed, P. and Goldberg, T. (2002) Cloning cultures: The social injustices of sameness, Ethnic and Racial Studies, 25 (6), 1066-1082.

European Commission (2000) Science policies in the European Union: Promoting excellence through mainstreaming gender equality: A report from the ETAN network on women and science, European Commission, Luxembourg.

European Commission (2009) The gender challenge in research funding: Assessing the European national scenes, European Commission, Luxembourg.

European Commission (2019) SHE figures 2018, European Commission, Brussels.

Greenspan, J., Craft, R., LeResche, L., Arendt-Nielsen, L., Berkley, K., Fillingim, R., Gold, M., Holdcroft, A., Lautenbacher, S., Mayer, E., Mogil, J., Murphy, A. and Traub, R. (2007) Studying sex and gender differences in pain and analgesia: A consensus report, Pain, 132, S26-S45.

Hanmer, J. (1990) Men, power and the exploitation of women, in J. Hearn and D. Morgan (eds), Men, masculinities and social theory, Unwin Hyman/Routledge, London, 21-42.

Hearn, J. (2001) Academia, management and men: Making the connections, exploring the implications, in A. Brooks and A. Mackinnon (eds), Gender and the restructured university, Open University Press, Buckingham, 68-89.

Hearn, J. (2004) From hegemonic masculinity to the hegemony of men, Feminist Theory, $5(1), 49-72$.

Hearn, J. (2015) Men of the world: Genders, globalizations, transnational times, Sage, London.

Hearn, J. (2017) Neoliberal universities, patriarchies, masculinities, and myself: Transnational personal reflections on and from the global North, Gender, rovné přiležitotosti, výzkum [Gender and Research], 18 (1), 16-41. Available at: www.genderonline.cz/ uploads/9ca00c579277882deab7f476e0833abafb2a3248_gender-01-2017-stat-1-hearn.pdf

Hearn, J. and Collinson, D. (2009) Men, diversity at work, and diversity management, in M. Özbilgin (ed), Equality, diversity and inclusion at work: A research companion, Edward Elgar, Cheltenham, 383-398.

Hearn, J. and Howson, R. (2019) The institutionalization of (critical) studies on men and masculinities: geopolitical perspectives, in L. Gottzén, U. Mellström and T. Shefer (eds), The Routledge international handbook of masculinity studies, Routledge, London, 19-30.

Hearn, J. and Husu, L. (2019) Age-gender relations in the academic profession: Putting the challenges of entry and early career into context, in T. Adams and M. Choroszewicz (eds), Gender, age and inequality in the professions, Routledge, London, 193-212.

Hearn, J., Nordberg, M., Andersson, K., Balkmar, D., Gottzén, L., Klinth, R., Pringle, K. and Sandberg, L. (2012) Hegemonic masculinity and beyond: 40 years of research in Sweden, Men and Masculinities, 15 (1), 31-55.

Hearn, J. and Pringle, K. (2006) European perspectives on men and masculinities: National and transnational approaches, Palgrave Macmillan, Houndmills.

HSV [Högskoleverket] (2003) Doktorandspegeln 2003, HSV Rapport, 28 R, Stockholm. HSV [Högskoleverket] (2008) Doktorandspegeln 2008, HSV Rapport, 23 R, Stockholm.

Lipman-Blumen, J. (1976) Toward a homosocial theory of sex roles: An explanation of the sex segregation of social institutions, in M. Blaxall and B. Reagan (eds), Women and the workplace, University of Chicago Press, Chicago, 15-31.

Lohan, M. and Faulkner, W. (eds) (2004) Men and masculinities, Special Issue on Masculinities and Technologies, 6 (4). 
Madera, J., Hebl, M. and Martin, R. (2009) Gender and letters of recommendation for academia: Agentic and communal differences, Journal of Applied Psychology, 94 (6), 1591-1599.

Matthews, C. (2016) Exploring the pastiche hegemony of men, Palgrave Communications, 2, article 16022 .

Messner, M. (1997) Politics of masculinities, Sage, Thousand Oaks, CA.

Moyer, B. and Tuttle, A. (1983) Overcoming masculine oppression in mixed groups, in Off their backs ... and on our own two feet, New Society Publishers, Philadelphia, 24-29.

Murgia, A. and Poggio, B. (eds) (2019) Gender and precarious research careers: A comparative analysis, Routledge, London.

O'Brien, M. (1981) The politics of reproduction, Routledge \& Kegan Paul, London.

Rosenfeld, D. and Faircloth, C. (eds) (2006) Medicalized masculinities, Temple University Press, Philadelphia.

Scambor, E., Wojnicka, K. and Bergmann, N. (eds) (2013) Study on the role of men in gender equality, European Commission, Brussels.

Schiebinger, L. (1987) The history and philosophy of women in science: A review essay, Signs, 12 (2), 305-332.

Symonds, M., Gemmell, N., Braisher, T., Gorringe, K. and Elgar, M. (2006) Gender differences in publication output: Towards and unbiased metric of research performance, PLoS One, 1 (1), e127.

UKÄ [University Chancellor's Office] (2016) Doktorandspegeln 2016. En enkät om studenternas studiesituation, UKÄ Rapport 18, Stockholm.

Wellcome Trust (1997) PRISM women and peer-review: An audit of the Wellcome Trust's decision-making process, Wellcome Trust, London.

Wennerås, C. and Wold, A. (1997) Nepotism and sexism in peer-review, Nature, 387 , 22 May, 341-343.

Willinsky, J. (2000) Tempering the masculinities of technology, in N. Lesko (ed), Masculinities at school, Sage, Thousand Oaks, CA, 253-282. 